\title{
Factors in the selection and matching of executive coaches in organisations
}

\author{
Ian Michael Wycherley and Elaine Cox
}

Business School, Oxford Brookes University, Oxford, UK

(Received 12 November 2007; final version received 13 December 2007)

\begin{abstract}
The objective of this paper is to explore factors that impact on the selection and matching of coaches with executives in organisations. Selection of coaches is seen to be of utmost importance and a number of different stakeholders are invariably involved in the selection and matching decisions. This conceptual paper uses critical analysis and discussion of a wide range of literature in order to explore the issues at play. The paper positions selection and matching within a conceptual framework and offers a systemic perspective on the organisational processes involved. It thus widens the debate on which actors exert influence. The paper argues that organisations should focus on preparing the executive to be better equipped to maximise their potential for being coached, focusing on selecting coaches, rather than being distracted by the matching question.
\end{abstract}

Keywords: coaching; mentoring; executive; matching; selection; diversity

\section{Introduction}

Selection and matching of coaches with coachees is considered an essential factor in the ultimate success of the coaching relationship. Joo argues that selecting executive coaches and matching them to individuals 'is critical in coaching effectiveness' (Joo, 2005, p. 480) whilst Atkinson suggests that 'a match is essential in forming a strong psychological bond' (Atkinson, 2005, p. 1). However, there is a danger that executives and other stakeholders may make ill-informed matching decisions based on factors such as the initial rapport between executive and coach.

In this paper, we first present a conceptual model that improves understanding of how different stakeholders desire involvement in selecting and matching decisions. Feldman and Lankau (2005) asked whether mismatches discussed in the mentoring literature might be similar to those in coaching. Building on this question, the paper draws on mentoring literature that can help with thinking through diversity issues such as the matching of gender or culture between executive and coach. Then, further analysis explores how a coach's personality and experience affect their perceived trustworthiness and ability to meet the executive's needs. Following each substantive section we set out implications for coaching. The discussion brings in further factors, offers suggestions for practitioners and uses the conceptual model to frame suggestions for further research. The conclusion summarises the contribution of the paper and future implications.

*Corresponding author. Email: imwycherley@brookes.ac.uk 


\section{Definitions and statement of selection and matching problem}

This paper uses the word 'coach' to refer to an individual providing coaching for an 'executive coachee'. The latter works in a 'client organisation' in which a Human Resources Department (HR) typically organises the coaching programme. Coaches are normally employed by an external coaching 'provider'. 'Selecting' refers to assessing coaches' external competence factors leading to a list of approved coaches (the coach pool). 'Matching' relates to attempts to identify a coach tailored to the individual executive's needs.

Executive coaching can concentrate on improving skills and performance directly. The focus may also include a developmental or free agenda (Fillery-Travis $\&$ Lane, 2006). For the purposes of this paper, the definition by Kilburg (1996), p. 142) is assumed:

Executive coaching is a helping relationship formed between a client who has managerial authority and responsibility in an organisation and a consultant ... to achieve a mutually identified set of goals, to improve his or her professional performance and personal satisfaction, and consequently to improve the effectiveness of the client's organisation.

\section{Selection and matching model}

In Figure $1 \mathrm{a}$ model of the selection and matching process is introduced in order to locate the issues that we consider to be important in connection with the selection

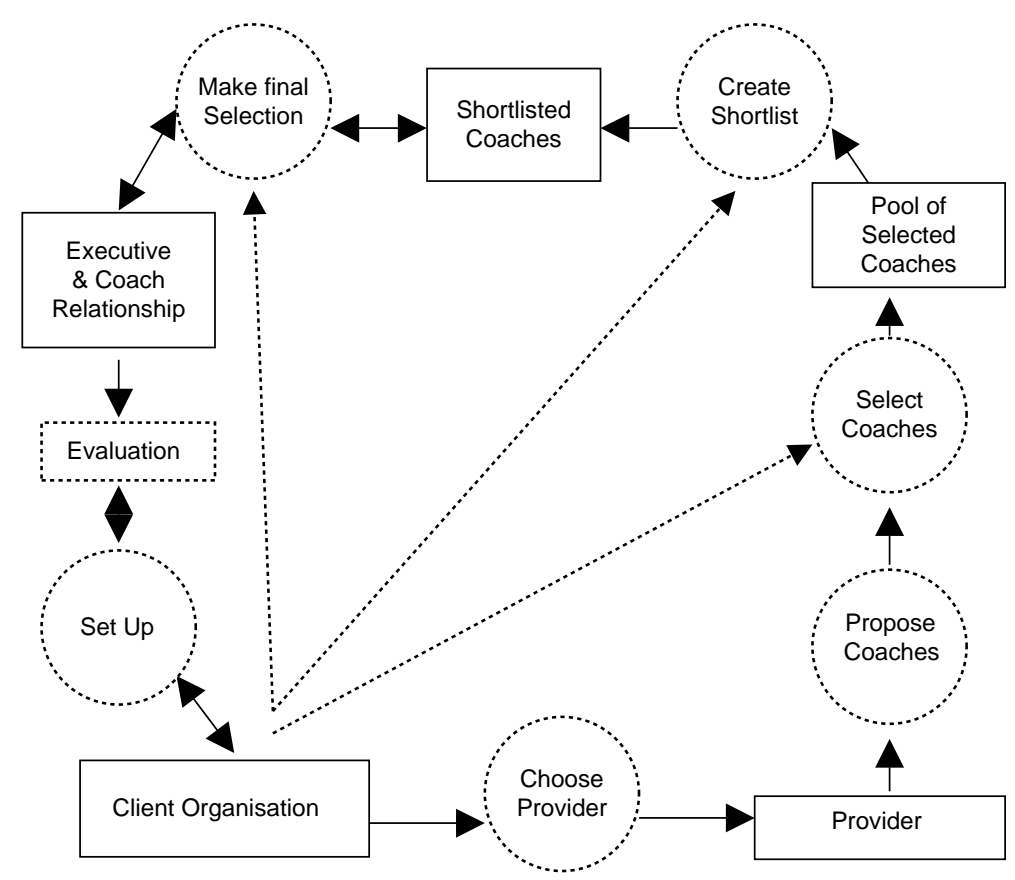

Figure 1. Context of Selection and Matching in Executive Coaching. 
and matching process. The discussion section that follows draws on a range of literature and uncovers some of the complex variations found in practice. For example, research by Judge and Cowell (1997) cited in Feldman and Lankau (2005) found that executives initiated roughly the same number of coaching interventions as their organisation.

The model in Figure 1 identifies different phases as follows:

Set up: The client organisation decides the objectives of executive coaching programme and identifies suitable executives. This may draw on a review or evaluation of previous coaching interventions.

Choose provider: The client organisation chooses coaching provider(s). Provider reputation may influence subsequent selection decisions.

Propose coaches: Providers propose suitable coaches to the client.

Select coaches: The client organisation selects a pool of coaches using checklists, interviews and assessment centres.

Create shortlist: The client organisation (normally HR) reviews the pool of coaches and matches two or three to the executive.

Make final selection: The executive chooses the coach from shortlist.

The model shows the client organisation's influence on the selecting, short-listing and matching phases using dotted lines. However, a number of different stakeholders want or need to be involved in choices at each phase and each may base their choices on a variety of factors. Below we begin our discussion of these factors and explore how they impact on achieving effective selection.

\section{Matching in the coaching context}

The importance of the matching decision has been discussed by Hall et al. (1999, p. 58), who suggest that 'it is an art to match temperament and learning styles for coaches and clients'. However, there are arguments and evidence to suggest that matching is more complex than merely an alignment between two personalities. Cranwell-Ward et al. (2004) see the critical issue in matching of mentors and mentees as being whether to aim for similarity or difference in order to achieve fast rapport and achievement of goals. The paradox here is that in defining executive coaching in terms of results, there may be a focus on short-term performance at the expense of long-term learning. Clutterbuck (1998) has suggested, for example, that a similarity in personality and experience means there are less personal development opportunities.

Furthermore, as Jarvis (2004, pp. 58-59 [Italics added]) notes, the executive coachee and client organisation are often both responsible for selection and matching decisions. She recommends that the client organisation consider the skills, experience and personality of prospective coaches when creating the shortlist, and suggests that the executive makes the final matching decision based 'on a 
degree of "chemistry". However, Jarvis also argues that it is important that the individual selects 'the most appropriate coach for their needs, and not just the one they like the most'. There are other authors who claim that the 'chemistry' between the coach and coachee plays a crucial role in matching (e.g. Chidiac, 2006; Conway, 1998; Hodgetts, 2002).

However, little is known about the role of 'chemistry'. It is rarely defined, and is a vague concept for practitioners and researchers. Both Bennett (2006) and Feldman and Lankau (2005) have suggested that further research in this area would help our understanding of the effects of matching.

Hodgetts (2002), p. 208) has argued that 'selecting executive coaches and matching them to individuals is a high art and a critical one.' He proposes three criteria for selecting the 'right coach':

1. Interpersonal skills that include self-awareness, listening and empathy, ability to deliver difficult feedback etc.

2. Perceived by the client as 'competent and trustworthy'.

3. Sufficient understanding of business and organisational politics.

Hodgetts claims that most errors in coach selection involve absence of one or more of these three. Kampa-Kokesch and Anderson (2001) support these criteria by concluding from a literature survey that business, management, leadership and political awareness is necessary.

If the client organisation uses a coach-provider, rather than dealing directly with the coach, there is an additional three-way contractual arrangement that needs careful consideration and management (see Figure 1). The provider may introduce a degree of matching when proposing coaches. For example, OPP (2007 p. 1), a provider of executive coaching, point out that they ensure 'the best possible fit between client and coach, based on both experience and personality'. The competency level of the coach in this phase could be seen as the remit of the coach-provider, but the client organisation should ensure that the provider has adequate coach-development, supervision and selection arrangements in place to support the work required. Similar developmental opportunities may be needed to support internal coaches too.

Overall, simple prescriptions to consider 'chemistry' in matching seem rather limited and imprecise. Other more complex factors may also be relevant to the selection and matching of executives with their coaches. Next three of these are considered: surface diversity factors, deep diversity factors and experience.

\section{Surface diversity factors - culture and gender}

Harrison et al. (1998, p. 97) have pointed out an important difference between surface level and deep level diversity. At the surface level are the readily detectable attributes such as race, ethnicity, sex and age, whilst the deep level includes differences in values, beliefs and attitudes. Whilst surface level diversity tends to affect rapport in initial stages of a relationship, they argue that 'as people interact to get to know one another, stereotypes are replaced by more accurate knowledge of each other as individuals' (Harrison et al., 1998, p. 99). Thus surface level factors are seen to be not as important over time as the deep level differences. 
In this section of the paper we look at examples of surface level diversity in some detail in order to assess their value and consider whether the recent research in the mentoring arena in relation to cultural and gender matching can have relevance for coaching.

\section{Cultural diversity}

Some of the most powerful arguments for matching in formal mentoring schemes are made in relation to cultural matching. For example, training materials produced in America, (NMC Training Curriculum, 2000, p. 18) state that the arguments for cultural matching are 'deeply embedded in minority groups' historical experience in the United States.' It is argued that a mentor from a different racial and ethnic background cannot understand the social and psychological conflicts of the mentee and therefore that deep levels of trust, sharing and cooperation will not be achieved.

Johnson-Bailey and Cervero (2004) have shared in detail the intricacies of their long-term mentoring relationship and discuss the common issues facing the crosscultural pairing. In particular they highlight trust between mentor and mentee, the acknowledged and unacknowledged racism, issues of power and paternalism and the benefits to both parties. They confirm that cross-cultural mentoring relationships are 'affiliations that exist between unequals' $(2004$, p. 5) and that issues of trust therefore become of utmost importance. They identify that much of the research on mentoring does not examine what they call 'the crisis of trust' and the 'inevitable instances of anger and guilt that happen in mentoring relationships'. Their suggestion is to stress the importance of ongoing and honest discussions about race and racism in cross-cultural mentoring situations (2004, p. 7) and to pair mentees with mentors with whom they share similar worldviews in order to increase the chances of success. Johnson-Bailey and Cervero further suggest that any power relationship is further magnified in cross-cultural mentoring since both people are in 'different locations in societal hierarchies of race and gender' (2004, p. 10).

A further issue is the problem of access to mentors of the same race. Even if it is deemed important to match the race of mentor and mentor, for a particular reason, it can be difficult for mentees to find someone of the same race within the organisation and so additional boundaries, such as level, location, function or gender may need to be considered (Blake-Beard et al., 2006).

However, Ragins (1997) has discussed how mentors benefit from cross-cultural relationships. She suggests that although all mentors obtain intrinsic and organisational outcomes, diversity outcomes are achieved only in cross-cultural relationships and include knowledge, empathy and skills related to interacting with individuals from different social groups. So there may be benefits for the organisation in consciously making cross-cultural pairings.

\section{Gender diversity}

Arguments for gender matching are also strong. For example, Cozza (2006), p. 18) believes that same-gender-mentoring relationships can be the "prerequisite for a necessary mutual understanding between mentor and mentee, in which the 
same-gender identity often facilitates the sharing of similar experiences and the discussion of themes perceived differently by men and women'.

Research by Ragins (1997) has explored how mentee gender, mentor gender, and the dyadic gender composition of the relationship can influence the mentoring received. According to Ragins, gender makes a difference in mentoring relationships because there are embedded stereotypes at play in the organisation. Thus the mentor and mentee of different genders will be members of groups that possess differing degrees of power within organisations (Ragins, 1997). For example, female mentees may be perceived as weaker and thus be accorded a greater degree of protection by male mentors. In addition, social psychology literature suggests that women are more likely than men to provide emotional support and informal counseling (Eisenberg \& Fabes, 1991). However, more recent studies have found no gender differences in the quality of mentoring received (Scandura \& Williams, 2001).

Some findings from research into same-gender dyads in mentoring suggest that homogeneity is preferable, while others suggest that cross-gender mentoring relationships, although more difficult to develop, have considerable rewards (Hurley, 1996). The female mentor-male mentee dyad is reported to be the least comfortable for both parties (Armstrong et al., 2002), perhaps because this pairing reverses traditional gender roles.

\section{Implications of surface diversity issues for coaching}

We have reviewed the two most common surface diversity issues in relation to matching in mentoring settings. We now consider the benefits and pitfalls of taking account of these factors in the selection of coaches.

The benefits of selecting a coach who is similar to the executive in relation to race, gender (and even age or sexual orientation) are that rapport building can be quicker to achieve. There may also be a greater understanding of relevant issues as discussed above. In a large American study of ethnic and gender matching between therapist and clients, Fujino et al. (1994) found that ethnic and/or gender matching were significantly associated with several aspects of the longevity of relationships.

It may also be advantageous to consider matching according to career path or professional or life experience, since shared experiences enable bonds to be forged quickly. The opportunity for role modelling is also manifest, although this is often perceived as undesirable and unethical and the pitfalls of matching on this basis could be collusion and narrowness of vision. There is also an issue regarding equality of opportunity within the organisation: it could be argued that coach or mentor selection should come under the same anti-discrimination laws as other recruitment activity in the organisation.

As in mentoring, there are also arguments on both sides for mis-matching the coach and the executive. The benefits include the diversity of perspectives that can be achieved. However, the main drawback is that the coach could lack a deeper awareness of the issues the executive may be facing.

In earlier research (Cox, 2005), it was argued that training for mentors would enable them to rise above personal considerations and differences when providing mentoring support and expertise, and that with preparation and training for the role 
they can be equally, if not more, effective than mentors chosen solely for their surface similarity. The argument stands for coaching: coaches can learn to build rapport through the right kind of training and so learn to compensate completely for any lack of natural affinity.

The challenges faced by the coach in relation to surface diversity, can therefore, in our opinion, be overcome to a large extent by adequate training and development. The coach can learn how to develop rapport, even if rapport is not instantly palpable. Similarly, the coach should have an awareness of his or her own biases, be able to empathise with the coachee's situation and try to understand challenges from the coachee's perspective as much as possible. Thus it may be the qualities of the mentor that matter most and cross-cultural mentoring may work as long as mentors are aware of their own cultural 'baggage' and remain sensitive to the needs of the mentee (Tierney \& Grossman, 1995).

Rosinski (2003) argues that it is also important for coaches working internationally, not just cross-culturally, to recognise issues of national culture and demographics and be aware of differences. For example, the issue of race is possibly more sensitive in the United States (Blake-Beard et al., 2006) and, due to shifting demographics, is likely to become more so in the future. Similarly, the Chinese culture places a different emphasis on compliance.

The reaction of the executive to opportunities to be coached by someone of a different gender or culture is also important to consider. Executives may need to be alerted to their prejudices in relation to diversity that may prevent them from building trust in their coach. They might need to be encouraged to experiment and learn from a coach who is different from themselves. This exploration could be done at the 'set-up' phase in preparation for coach selection.

\section{Deep diversity factors - values and personality}

There is little more than anecdotal evidence to support matching on personality. Similarly chemistry, which is often interpreted as initial rapport, is an unreliable indicator of a successful coaching relationship. This section examines the notion of rapport and its links to trust and values in the coaching literature and then looks at personality factors (Harrison et al., 1998).

\section{Values}

In the Surrey leadership programme (Gray \& Goregaokar, 2007, p. 8), details of pre-selected coaches with photographs were sent to interested small and medium sized (SME) executives. The SME managers found the final matching decision difficult and subjective: 'in the end it often came down to what the coach looked like and (how they) spoke...' This example illustrates the need to support executives in their matching decisions, since basing a decision on appearance and initial liking and rapport can be potentially misleading. Placing too much emphasis on what it feels like when seeing or meeting a potential coach may leave the executive potentially vulnerable to making a choice based on stereotyping and surface diversity factors.

Bluckert (2005) argues that executives who trust their coach are likely to be more committed and that rapport can be built. Trust, he suggests, is important and 
relates to a coach's integrity and competence. The rapport-building skills of the coach are likely to be a deciding factor and form the base from which trust can develop.

Hale (2000) and Nielson \& Eisenbach (2003) suggest matching of values to build rapport, whilst Young and Perrewe (2000, p. 617) suggest that trust comes from enacting 'role behaviours that are valued by the other'. This growth of trust overtime is identified in research carried out by Cox (2005), suggesting that initial decisions about a potential coach's trustworthiness and credibility may therefore be superficial. Floyd (1999, p. 310) also identified a number of studies that claim that reciprocity, which is considered important in a good coaching relationship, is linked to 'increased liking, trust and relational intimacy'.

\section{Personality}

Although some writers argue for personality matching, the evidence is limited and contradictory. Engstrom (2004), for example, found that matching on extraversion correlated with higher mentee motivation and career development whilst matching agreeableness correlated with higher perceptions of success. Armstrong et al. (2002) support matching in mentoring, but only found limited evidence to suggest that similar cognitive styles can directly help communication and indirectly improve rapport. Luecke (2004) advises that mentors should have compatible temperaments or styles. However, a sample of 117 single session coaching interventions by Scoular \& Linley (2006, p. 11) offers evidence that learning is better when temperaments are different. Their findings suggested that 'in pairings differing on temperament, the coach may instinctively come from a different perspective, and perhaps challenge coachee assumptions more, with this more complex interaction leading to higher performance outcomes'.

In relation to developmental levels, coaches themselves as well as coach-providers may be familiar with the Rooke and Torbert (2005) 'action logics' model of leadership development, which suggests that leaders need to understand the level of their current action logic in order to develop further. However, relatively little is known about the impact of different stages of adult development on the quality of interaction between the participants and there is even less research on how the match or mismatch of the stages might affect the coaching process. However, it could be that ensuring that the coach is at the right 'level' may also be vitally important. Bachkirova and Cox (2007), for example, claim that understanding cognitivedevelopmental levels is crucial in coach education and development.

It should be remembered that personality styles, types and levels of development are only heuristics. They are mental shortcuts that help us classify people more quickly and, if used judiciously, provide an organising principle upon which to base decisions. However, they need to be understood for what they are and used with caution: they are not reliable portrayals of people and could lead to bias and distortion of perception. The evidence suggests that psychometric tests and developmental ratings are not an absolute measure of personality characteristics, or attitudes, but rather a clue to existing tendencies. An individual's personality type and developmental level can change over time and also be influenced by conscious personal decisions and developmental opportunities. 


\section{Implications of deep diversity issues for coaching}

Personality instruments have a role in coaching itself, and as a research tool, but there is no substantial evidence to support their use in selection or matching. We would argue therefore, that in the set-up phase, HR should educate executives about the potentially misleading role of initial rapport and coach appearance in order to minimise matching errors. Coach-providers may want to ensure that the coaches they use for particular executive coaching assignments have a good level of cognitive and emotional development, but should recognise that matching by type may not ensure a successful relationship.

\section{Experience Factors}

There are calls not only to match the coachee's need to the coach's style (Horner \& Humphrey, 2005) but also to their expertise (Fillery-Travis \& Lane, 2006). Thus another factor that it is important to evaluate is the relevance of the coach's experience. Although expertise in a relevant field is central to mentoring (Kram, 1988), direct experience of the same industry or organisation, as claimed, is not usually necessary in coaching, because learning and development is the main goal (Jarvis, 2004).

If it is assumed that all executive coaches would be experienced in coaching, then the main area of additional experience needed would be business knowledge, skill and understanding (Hodgetts, 2002). Coaches who have held positions of authority appeal to many executives who want useful suggestions (Hall et al., 1999). Stern (2004) argues that most executives prefer a coaching approach that is practical, concrete and results-oriented, and this means that business experience lends credibility. However, it may be difficult to establish what kind of business experience is relevant. Clutterbuck and Megginson (1999) found, for example, that ownermanagers do not readily accept suggestions from middle managers in larger organisations. Similarly Gray and Goregaokar (2007) found that most SME owner-managers thought that experience of coaching in large companies was a negative factor.

A danger may also be that coaches with a business background may end up giving consultancy to stuck executives (Gray \& Goregaokar, 2007), and are especially vulnerable to the 'trap of influence' in which they exploit their ability to persuade executives to make certain decisions (Berglas, 2002).

\section{Implications of experience for coaching}

It is important for the executive and client organisation to be as clear as possible in the set-up phase about the coaching agenda. Executives requiring practical advice may need to consider internal mentors or consultants, whereas a more developmental agenda will be less tied to a coach's own business experience and rely more on their experience and development as a coach. If providers mapped their coaches' business and coaching competencies as suggested by Ahern (2003), this might help HR make better selection decisions. 


\section{Discussion}

This section questions the role of 'chemistry' and introduces further important factors beyond the issues of diversity and experience discussed so far. It offers suggestions for practitioners and uses the conceptual model to inform recommendations for further research.

It could be argued that properly trained coaches should be able to coach any executive on any purely developmental coaching agenda (i.e. no specific technical knowledge needed), provided there are no logistical or language barriers. Whilst Feldman and Lankau (2005) ask whether organisations may implicitly match coaching style with executive needs, a good coach should be able to vary their style as required by the situation. In practice however, the situation is more complex. Given the constraint that time pressure places on executive personal development (Jackson et al., 2003), it is crucial to secure the active commitment of the executive. However, the evidence on how executive participation in matching might affect commitment is unclear. Mentees usually have a choice of mentors (Klasen \& Clutterbuck, 2002), yet there is mixed evidence on whether mentee involvement in matching improved the result (Hezlett and Gibson, 2005; Wanberg et al., 2003). One city organisation assigned coaches with no coachee choice and had limited success (Palmer, 2003). By contrast, PricewaterhouseCoopers (PwC) (Leiman et al., 2005) offered only one choice to executives, which the coachee normally accepted.

The ability of an executive to manage the coaching relationship is also in doubt. As McDermott et al. (2007, p. 35) state: 'most executives do not understand coaching provider differentiators or how they should use a coach; they simply want to complete the coaching process'.

The research evidence in relation to matching in coaching is mixed and partial. One study of HR managers showed problems with matching were the lowest potential drawback (Dagley, 2006) and Thach, (2002) reported that whilst the coaching relationship was the biggest factor in explaining outcomes, only 9 out of 114 executives complained of poor chemistry. It would be useful to perform further studies on the effectiveness of matching decisions and the effects of surface and deep diversity factors on executive coaching relationships. Executives may also need help in managing termination of inappropriate relationships.

Whilst Scandura (1998) and Ragins et al. (2000) show that some dysfunctional mentoring relationships simply carry on, Fanasheh (2005) found CEOs who had experienced failed coaching would not hire another one. Feldman and Lankau's (2005) call for more outcome research in coaching is helpful, especially if such research were to include a definition of what constitutes an effective or ineffective relationship match.

A more systemic analysis of selection and matching reveals that executives may seek a coach to fill a hole in their development network (Chandler \& Kram, 2005). If organisations really wish to develop their executives, they should focus on helping them to learn how to make the most of coaching and design organisational standards and review processes that support executives' trust in the selection and matching process. An example is PwC's preference for individual coaches rather than larger suppliers so that it can apply PwC's demanding quality control process (Leiman et al., 2005). Ultimately executives should learn to choose coaches who are dissimilar if they really want to learn and develop. 
The principal contribution of the conceptual model is that it extends Jarvis's (2004) work by helping us to structure our understanding of the organisational context of selection and matching of executive coaches. Figure 1 is a model of one type of executive coaching managed by the organisation, but it could also form the basis of future research into some of the other variations evident in practice. Example of this complexity and variation are when selection and matching is further complicated through team coaching groups of executives, or when the executive's line manager becomes involved in the final match. Moreover, the trend towards organisations using internal coaches more frequently (Hall, 2006) brings relationship history and factors such as power and sponsorship to centre stage. There may be overlaps with existing mentoring schemes in this case. The risks of low awareness are especially relevant to SMEs where executives may have minimal input from HR.

One limitation of the proposed conceptual model is that the executive and coach relationship is contained within a single phase and not explored. Feldman and Lankau (2005) describe the coaching literature as treating the coaching relationship as a 'black box', and O'Broin and Palmer (2006) agree that little is known about the dynamics of coaching relationships and their effects on outcomes. When investigating coaching in future, researchers could expand the model presented here by identifying wider systemic factors that inevitably impact the relationship.

\section{Conclusion}

This paper has presented a context model of the selection process in executive coaching and has argued that matching coaches with executives based on the right 'chemistry' and other surface diversity factors may be neither necessary nor effective. The model highlights the processes involved in the selection of coaches by organisations and the relationships between these processes and the different stakeholders. It can be seen, for example, that the different stakeholders in the process need to understand how everybody wants to have a say in matching in order to achieve desired outcomes. If they do not, then the cumulative costs may well exceed the cost of the coaching itself.

The paper also explored the mentoring literature, which offers useful pointers for client organisations and executives who wish to coach explicitly on surface diversity issues, such as culture and gender. It was further noted how selection choices based on matching surface and deep factors impacts on rapport in the initial stages of the relationship and that these factors become less important over time as trust is built.

Raising the awareness of executives and others involved in the selection process to the prejudice inherent in matching can contribute to their ability to form an advantageous coaching relationship. The issue of the experience of the coach was also highlighted as an important consideration in the selection of coaches.

The issues raised in this paper increase in importance with the growing popularity of executive coaching as a management development intervention. They have implications for the preparation of executives in advance of coaching, for coach provider marketing and or HR selection decisions. Our tentative conclusions are that there are benefits from focusing on the objective selection of coaches using robust standards and criteria, rather than relying on surface or deep diversity factors or subjective matching approaches based on initial rapport. 


\section{Notes on contributors}
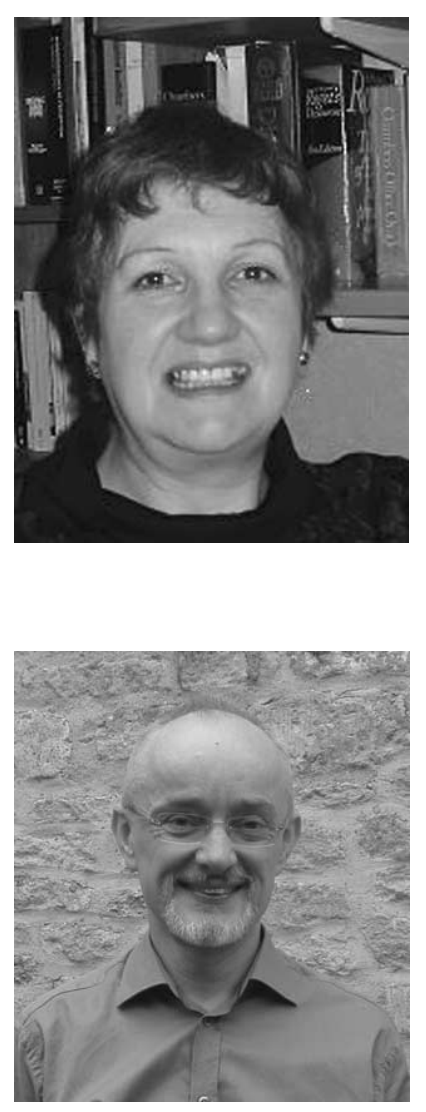

Elaine Cox, $\mathbf{P h D}$ is Principal Lecturer and Leader of the Research Centre for Coaching and Mentoring at Oxford Brookes University. She has completed a PhD in Educational Research, focusing on mentor development in the voluntary sector and has been publishing since on the various topics of adult development and coaching. Dr Cox is the Editor-in-Chief for the International Journal of Evidence Based Coaching and Mentoring.

Ian Wycherley is a Senior Lecturer at Oxford Brookes Business School where he leads courses on career management, personal development and environmental sustainability. He is a coach and business storyteller, working with individuals, groups and organisations.

\section{References}

Ahern, G. (2003). Designing and implementing coaching/mentoring competencies: A case study. Counselling Psychology Quarterly, 16(4), 373-383.

Armstrong, S.J., Allinson, C.W., \& Hayes, J. (2002). Formal mentoring systems: An examination of the effects of mentor/protégé cognitive styles on the mentoring process. Management Studies, 39(8), 1111-1137.

Atkinson, P. (2005). Rapport building - matching the client style. Coach the Coach. Retrieved on August 15, 2007 from http://philipatkinsonconsulting.com/pdf33.pdf

Bachkirova, T., \& Cox, E. (2007). Cognitive-Developmental approach to the development of coaches. In S. Palmer \& A. Whybrow (Eds.), Handbook of Coaching Psychology. London: Routledge.

Bennett, J.L. (2006). An agenda for coaching-related research: A challenge for researchers. Consulting Psychology Journal: Practice and Research, 58(4), 240-249.

Berglas, S. (2002). The very real dangers of executive coaching. Harvard Business Review, June, 86-92.

Blake-Beard, S.D., Murrell, A., \& Thomas, D. (2006). Unfinished business: The impact of race on understanding mentoring relationships. Harvard Business School working paper available from http://hbswk.hbs.edu/item/5499.html 
Bluckert, P. (2005). Critical factors in executive coaching - the coaching relationship. Industrial and Commercial Training, 37(5), 336-340.

Chandler, D.E., \& Kram, K.E. (2005). Applying an adult developmental perspective to developmental networks. Career Development International, 10(6/7), 548-566.

Chidiac, M-A. (2006). Getting the best out of executive coaching: A guide to setting up a coaching process. Development and Learning in Organisations, 20(3), 13-15.

Clutterbuck, D. (1998). Learning alliances. London: Institute of Personnel and Development.

Clutterbuck, D., \& Megginson, D. (1999). Mentoring executives and directors. Oxford: Butterworth-Heinemann.

Conway, C. (1998). Strategies for mentoring: A blueprint for successful organizational development. Chichester: Wiley.

Cox, E. (2005). For better, for worse: The matching process in formal mentoring schemes. Mentoring \& Tutoring, 13(3), 403-414.

Cozza, M. (2006). Diversity management: mentoring to improve gender differences, FSAM VIIIth World Congress. Retreived August 15, 2007 from http://www.ctwcongress.de/ifsam/ download/track_16/pap00501_001.pdf

Cranwell-Ward, J., Bossons, P., \& Gover, S. (2004). Mentoring: A Henley review of best practice. Basingstoke: Palgrave Macmillan.

Dagley, G. (2006). Human resources professionals' perceptions of executive coaching: Efficacy, benefits and return on investment. International Coaching Psychology Review, 1(2), 34-45.

Eisenberg, N., \& Fabes, R.A. (1991). Prosocial behavior and empathy: A developmental perspective. In M. Clark (Ed.), Review of personality and social psychology: Altruism and prosocial behavior 12 (pp. 34-61). Beverly Hills, CA: Sage.

Engstrom, T. (2004). Variation in mentoring outcomes: An effect of personality factors? In D. Clutterbuck \& G. Lane (Eds.), The situational mentor: An international review of competences and capabilities in mentoring. Aldershot: Gower.

Fanasheh, S. (2005). Executive coaching: A perception of the chief executive officers of the most successful fortune 500 companies. Retrieved on August 15, 2007 from www.dissertation.com

Feldman, D., \& Lankau, M.J. (2005). Executive coaching: A review and agenda for future research. Journal of Management, 31(6), 829-848.

Fillery-Travis, A., \& Lane, D. (2006). Does coaching work or are we asking the wrong question? International Coaching Psychology Review, 1(1), 23-35.

Floyd, K. (1999). To match or not to match: Effects of behavioral congruence on interpersonal connectedness. Social Psychology, 139(3), 309-322.

Fujino, D.C., Okazaki, S., \& Young, K. (1994). Asian-American women in the mental health system: An examination of ethnic and gender match between therapist and client. Journal of Community Psychology, 22(2), 164-176.

Gray, D., \& Goregaokar, H. (2007). Executive coaching in SMEs-experiences and impact of the coaching process. 8th International Conference on Human Resource Development Research and Practice Across Europe. Oxford: Oxford Brookes University.

Hale, R. (2000). To match or mis-match? The dynamics of mentoring as a route to personal and organisational learning. Career Development International, 5(4/5), 223-234.

Hall, D.T., Otazo, K.L., \& Hollenbeck, G.P. (1999). Behind closed doors: What really happens in executive coaching. Organizational Dynamics, Winter, 39-52.

Hall, L. (2006). Inside job. People Management, 12(16), 34-36.

Harrison, D.A., Price, K.H., \& Bell, M.P. (1998). Beyond relational demography: Time and the effects of surface- and deep-level diversity on work group cohesion. Academy of Management, 41(1), 96-107.

Hezlett, S.A., \& Gibson, S.K. (2005). Mentoring and human resource development: Where we are and where we want to go. Advances in Developing Human Resources, 7(4), 446-469.

Hodgetts, W. (2002). Using executive coaching in organisations. In C. Fitzgerald \& J.G. Berger (Eds.), Executive Coaching (pp. 203-224). Mountain View, CA: Davies-Black. 
Horner, C., \& Humphrey, S. (2005). Delivering the coaching elite to Unilever. Strategic HR Review, 5(1), 8-9.

Hurley, A.E. (1996). Challenges in cross-gender mentoring relationships: Psychological intimacy, myths, rumours, innuendoes and sexual harassment. Leadership and Organization Development, 7(3), 42-49.

Jackson, S., Farndale, E., \& Kakabadse, A. (2003). Executive development: Meeting the needs of top teams and boards. Management Development, 22(3), 185-265.

Jarvis, J. (2004). Coaching and buying coaching services. London: CIPD.

Johnson-Bailey, J., \& Cervero, R. (2004). Mentoring in black and white: The intricacies of cross-cultural mentoring. Mentoring and Tutoring, 12(1), 8-21.

Joo, B.-K.B. (2005). Executive coaching: A conceptual framework from an integrative review of practice and research. Human Resource Development Review, 4(4), 462-488.

Judge, W.Q., \& Cowell, J. (1997). The brave new world of executive coaching. Business Horizons, 40(4), 71-77.

Kampa-Kokesch, S., \& Anderson, M.Z. (2001). Executive coaching: A comprehensive review of the literature. Consulting Psychology Journal: Practice and Research, 53(4), 205-228.

Kilburg, R. (1996). Towards a conceptual understanding and definition of executive coaching. Consulting Psychology Journal: Practice and Research, 48(2), 134-144.

Klasen, N., \& Clutterbuck, D. (2002). Implementing mentoring schemes: A practical guide to successful programs. Oxford: Butterworth-Heinemann.

Kram, K. (1988). Mentoring at work. London: Lanham.

Leiman, A., Moscovici, F., \& McMahon, G. (2005). Essential business coaching. London: Routledge.

Luecke, R. (2004). Coaching and mentoring: How to develop top talent and achieve stronger performance. Boston, MA: Harvard Business School Press.

McDermott, M., Levenson, A., \& Newton, S. (2007). What coaching can and cannot do for your organization. Human Resource Planning, 30(2), 30-37.

Nielson, T.R., \& Eisenbach, R.J. (2003). Not all relationships are created equal: Critical factors of high quality mentoring relationships. International Journal of Mentoring and Coaching, 1(1). Available at www.emccouncil.org/uk/journal.htm

NMC Training Curriculum (2000). Module 1: Targeted mentor recruiting. Retrieved 15 August 2007 from http://www.nwrel.org/mentoring/pdf/mod1.pdf

O'Broin, A., \& Palmer, S. (2006). The coach-client relationship and contributions made by the coach in improving coaching outcome. The Coaching Psychologist, 2(2), 16-20.

OPP (2007). Executive coaching for leadership development, OPP Ltd. Retrieved August 15, 2007 from www.opp.eu.com (Consultancy).

Palmer, B. (2003). Maximising value from executive coaching. Strategic HR Review, 2(6), 2629.

Ragins, B. R. (1997). Antecedents of diversified mentoring relationships. Vocational Behavior, 51(1), 90-109.

Ragins, B.R., Cotton, J.L., \& Miller, J.S. (2000). Marginal mentoring: The effects of type of mentor, quality of relationship, and program design on work and career attitudes. Academy of Management, 43(6), 1177-1194.

Rooke, D., \& Torbert, W.R. (2005). Seven Transformations of leadership. Harvard Business Review, 83(4), 67-76.

Rosinski, P. (2003). Coaching across cultures: New tools for leveraging national, corporate and professional difference. London: Nicholas Brealey Publishing.

Scandura, T.A. (1998). Dysfunctional mentoring relationships and outcomes. Management, 24(3), 449-467.

Scandura, T. A., \& Williams, E. A. (2001). An investigation of the moderating effects of gender on the relationships between mentorship initiation and protégé perceptions of mentoring functions. Vocational Behavior, 59(3), 342-363. 
Scoular, A., \& Linley, P.A. (2006). Coaching, goal-setting and personality type: What matters? The Coaching Psychologist, 2(1), 9-11. Retrieved August 15, 2007 from www.bps.org.uk/ coachingpsy/publications.cfm

Stern, L.R. (2004). Executive coaching: A working definition. Consulting Psychology Journal: Practice and Research, 56(3), 154-162.

Tierney, J.P., \& Grossman, J.B. (1995). Making a difference: An impact study of big brothers big sisters. Philadelphia, PA: Public/Private Ventures.

Thach, E.C. (2002). The impact of executive coaching and 360 feedback on leadership effectiveness. Leadership and Organization Development Journal, 23(4) 205-214.

Young, A., \& Perrewe, P (2000). What did you expect? An examination of career-related support and social support among mentors and protégés. Journal of Management, 26(4), 611-632.

Wanberg, C.R., Welsh, E.T., \& Hezlett, S.A. (2003). Mentoring research: A review and dynamic process model. In J.J. Martocchio \& G.R. Ferris (Eds.), Research in Personnel and Human Resources Management, 22. Oxford: Elsevier Science. 
Copyright of Coaching: An International Journal of Theory, Research \& Practice is the property of Routledge and its content may not be copied or emailed to multiple sites or posted to a listserv without the copyright holder's express written permission. However, users may print, download, or email articles for individual use. 